\title{
A Survey on Efficiency in PV Systems with DC-DC Converter
}

\author{
Geetha D. K. \\ Dept. of Electrical \& Electronics \\ Bangalore Institute of Technology
}

\author{
P. Pramila \\ Prof \& Head \\ Dept. of Electrical \& Electronics \\ Bangalore Institute of Technology
}

\begin{abstract}
The evaluation of power electronics has emerged since last few decades ago. The advancement in the power engineering has made many advantages as per cost, performance and size point of view. In recent years, the power electronics is used in many aspects of commercial, utility, military, transportation, aerospace, etc. A part of power electronics is DC-DC converter, and it has applicability in computers, spacecraft units, laptops, telecommunications and motor drives. The photovoltaic based energy generation is the modern way of generating the energy and is adopted all over the world. But the efficiency in power generation by the photovoltaic system varies with the climatic condition. To achieve better efficiency, DC-DC converter can be used. The technique called maximum power point tracking (MPPT) helps in efficiency optimization. This paper presents the survey over the existing energy optimization techniques; further efficiency optimization for future study is mentioned.
\end{abstract}

\section{Keywords}

DC-DC converter, Efficiency, MPPT, Photo Voltaic model

\section{INTRODUCTION}

Power electronics (PE) is intended to convert and control the electrical energy by using semiconductor device (switching mode). The PE adopted in many aspects of commercial, aerospace, etc. [1]. One of the applications in power engineering is DC-DC converter gives regulated voltage. The $\mathrm{dc}-\mathrm{dc}$ converters can be applied in power systems, fuel cell power system, photovoltaic power system, UPS systems, hybrid electric vehicles/electric vehicle, textile mills, home appliances, wind systems, robotics, paper mills, pumps, etc. With all the applicability in various high-efficiency power equipment, PE also provides high productivity along with enhanced product quality that will help in modern automated business units $[1,2,3]$.

In DC-DC converter, the efficiency is considered as major characteristic, more commonly for battery based systems. In this type of the systems, electrical and thermal losses may occur. These factors may play a role in system cost, hardware cost, etc., $[1,2]$. The usual DC-DC converter size is very much small and has a low weight. Any systems overall performance depends on the battery power capacity. Hence many works is focusing on improving or bringing the efficiency in power supplies, so that the cost and required cooling is reduced $[2,3]$.
Today, the world has adopted many renewable and easily available resources to generate the electric power. Among these resources, the solar rays of the sun are easily available resources by which the electric energy is generated. The solarbased energy system is commonly known as photovoltaic (PV) system. The cost of a photovoltaic cell is very high and its efficiency varies with climatic conditions like rainy, foggy, etc., and even depends on the shadows of the building, falling over the solar panel. In today's generation, the supply power needs to meet the entire load. It is being surveyed that efficiency of supply is needed to achieve the overall load. The proper optimization approach will help in achieving the load needs. In that sense over the year's study has taken place to meet the load needs. The fact is that the optimization concept of a power electronics composed of many aspects like mass, efficiency, temperature, etc. The DC-DC converter also helps to achieve the better efficiency in PV models.

This survey paper presents the survey of various existing efficiency optimization techniques. Section 2 describes photovoltaic system including types and efficiency factor. Section 3 describes the DC-DC converter and PV energy. Section 4 discusses the MPPT; Section 5 gives Survey of Existing research work in efficiency optimization techniques for PV modules. Section 6 describes issues in PV system, Section 7 discusses advantages and disadvantages of PV system. By surveying the recent research work, the research gap is described in section 8 . Section 9 frames the future study flow for efficiency optimization and Section 10 gives the conclusion for the paper.

\section{PHOTOVOLTAIC SYSTEM}

A system that generates the electrical energy by exposing to the solar radiations or by the photoelectric effect is known as photovoltaic or PV system. A PV system consists a number of solar cells which can be connected in parallel or series array pattern based on the voltage or current requirement. The connection of PV cells or solar cells can be done parallel to get the maximum output current, while the solar cells series connection is done to have maximum output voltage $[6,7]$. Recently many countries are adopted the PV-based energy generation unit to get the long-term solution for the load demands. The maintenance cost of PV cell is very less. The non-linearity in the PV system is a major issue that can affect the efficiency of power generation and also, the irradiation issues like a cloud, buildings shadows, etc. The block diagram of PV generation is represented with Figure 1 [7]. 


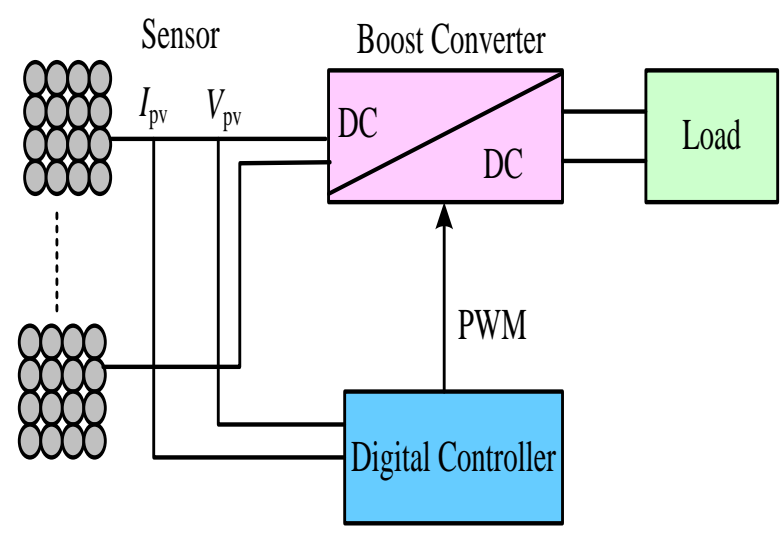

Figure 1. Block Diagram of PV system

\subsection{Types of Photovoltaic System}

The functionality, configurations and operation of PV system are classified as grid interfaced PV system and standalone PV system [7].

- Grid interfaced PV System: These systems are made to operate the PV system in parallel and interfaced with the grid. This system mainly composed of DC to AC conversion unit known as an inverter. This type of PV system can be operated by interfacing with grid [3].

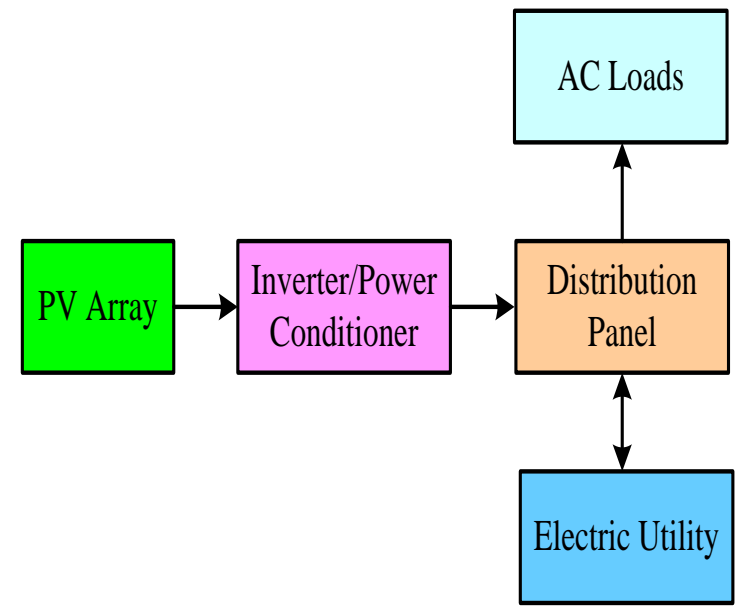

Figure 2. Block Diagram of Grid Interfaced PV System

Standalone PV Systems: These systems operate without any dependency over the grid and also on supply loads. This PV system is directly coupled system and works during the sun light and it will not store the generated power. These systems are used for running the fan, water pumping, etc. Block diagram of Standalone PV system is shown in figure. $3[6,7]$.

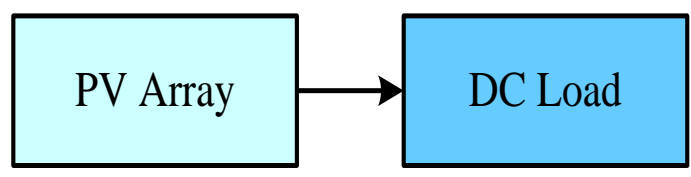

Figure 3. Standalone PV System

\subsection{Efficiency Factor in DC-DC converter}

In power electronics system, the efficiency of DC-DC converter is depends on output power and input power. i.e.,
$\eta=O u t_{P} / I n_{P}$

Where, $\eta$-Efficiency

$O u t_{P}$ - Output power

$I n_{P}-$ Input power

The portable devices like laptops, mobile phones, etc., requires low voltage and to have better battery life, DC-DC converter is necessary. Also, the DC-DC converter improves the load efficiency [8]

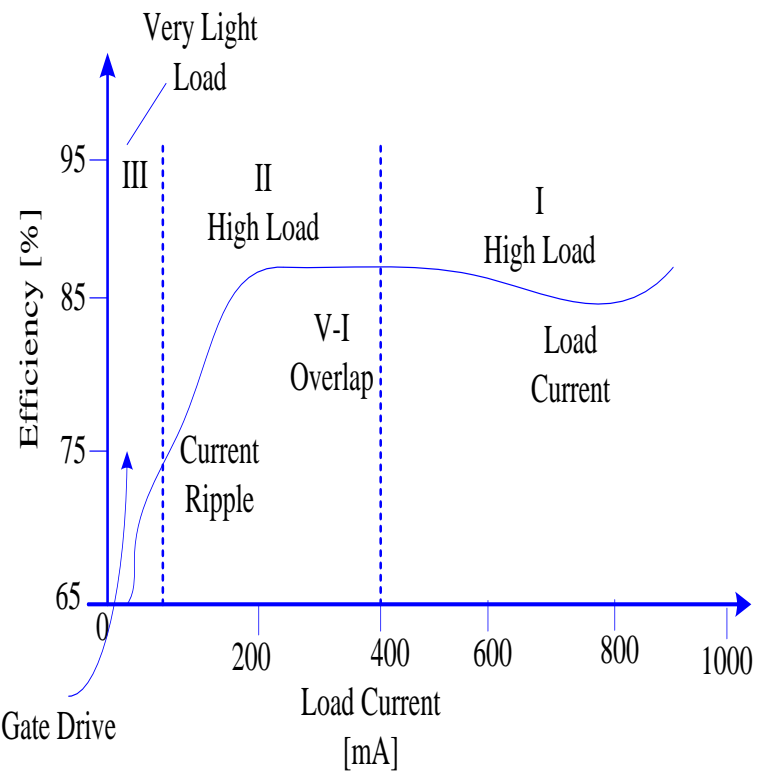

Figure 4. DC-DC Converter Efficiency Curve

In the figure 4., the efficiency variation in DC-DC converter is represented. At region I or high load condition, the losses of the dominant power taken as current load losses caused by its conduction. The condition II or light load condition, where the power losses take place by RMS losses and current ripples. The region III represents very light load condition $[8,9]$.

\section{DC-DC CONVERTER AND PHOTO VOLTAIC ENERGY}

The major function of a DC-DC converter is to convert the unregulated voltage into regulated voltage. Once the voltage conversion is done, the voltage will be adjusted to required voltage under various conditions. The advantage of DC-DC converter is that it provides high power, noise-free power conversion. The feature of DC-DC converter includes a wide range of voltage conversion and protection against overvoltage.

The DC-DC converter can function two different tasks. One interfacing of PV models and the other is interfacing with a grid to attain maximum power point. The DC-DC converter can be classified based on application, switching mode and current mode. The DC-DC converter can be of isolated and non-isolated types. The isolation type of converter is the barrier between the input and output.

The non-isolated type of DC-DC converter includes Buck, Buck-Boost, Boost, Cuk and SEPIC converter. The buck type of DC-DC converter converts the high voltage into low voltage. The input voltage will be modulated by using pulse 
width modulation (PWM) to attain Maximum Power Point (MPP). The boost type of converter converts the unmodulated voltage to required high voltage. This voltage converter has four kinds of parameters to boost the efficiency, i.e., coupled inductor, switched capacitor, coupled inductor \& switched capacitor and switched capacitor \& coupled inductor.

To get the maximum power point, several voltage levels need to have balanced current flow in DC-DC converter. The use of MOSFET in a boost converter will avoid the over voltage flow. Both buck and boost converter is considered as a buckboost converter that exhibits the properties of both converters $[10,11]$

\section{MAXIMUM POWER POINT \\ TRACKING}

To get the maximum power efficiency even in the different climatic condition and also under different load condition, maximum power point tracking (MMPT) technique is used. There exist various MPPT techniques to improve the efficiency in the photovoltaic system like Incremental conductance (IC) type, artificial neutral network (ANN), perturbation \& observation (P\&O) type, fuzzy logic (FL) type, particle swarm optimization (PSO), etc. All the above MPPT techniques will overcome the issues like non-linearity in PV module and shadows on PV module.

\subsection{Incremental Conductance (IC) Type of MPPT}

This MPPT technique gets better power tracking. The technique tracks the nature condition rapidly [12]. The MPP of PV curve based on IC type MPPT technique is given in figure 6. For MPPT, ratio of change in current (dI) and change in voltage $(\mathrm{dV})$, calculation along with conductance $(\mathrm{I} / \mathrm{V})$. The working flowchart from the left and right side of this MPPT technique is represented [7].

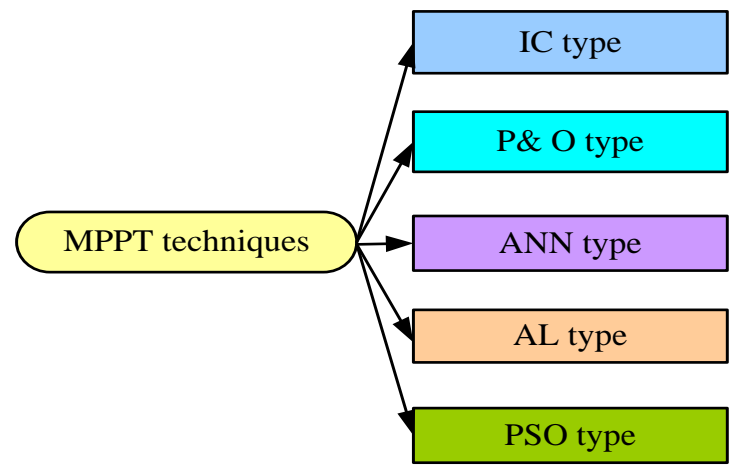

Figure 5. MPPT Techniques

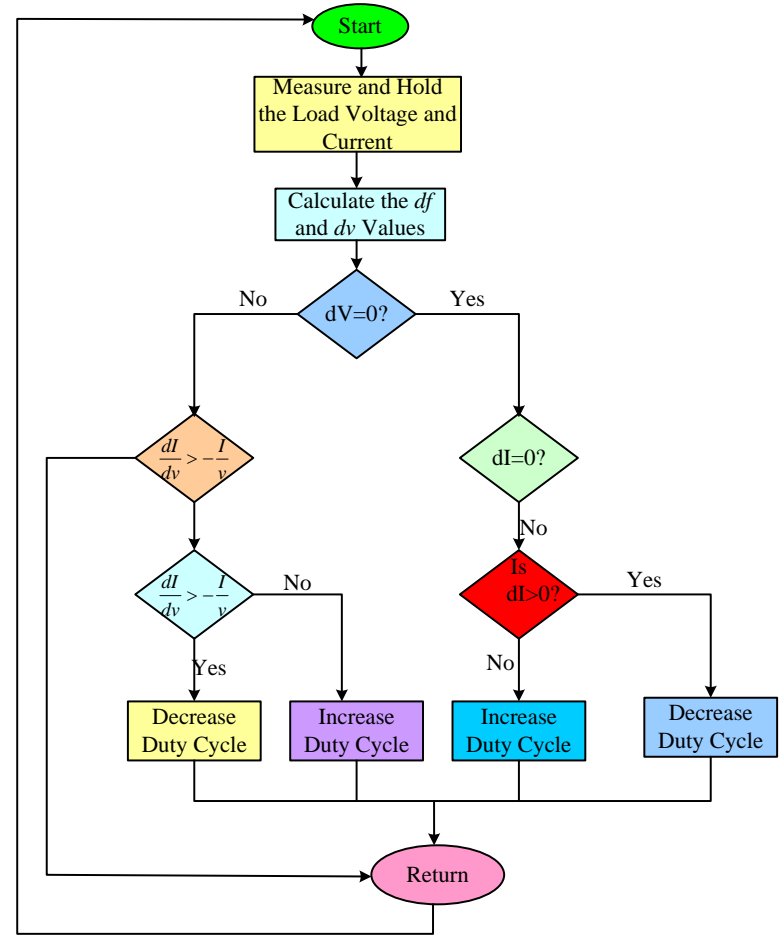

Figure 6. Flow Chart of Incremental Conductance

\subsection{Perturbation and Observation (P\&O) type of MPPT}

This technique is very useful and easily adoptable for PV array which is radiation direction perturbed. In this case, the power is drained because of PV array increases, the operating point will move towards maximum point and brings back to radiation direction. If the power drain by PV array decreased, then automatically the operating point will move away from the radiation direction. A drawback of this MPPT technique works at steady state. The moving of operating point towards MPPT will make wastage of energy [12, 13, 14]. The response speed of this technique is very slow and incremental power change can be measured as $\Delta \mathrm{P}$. In case $\Delta \mathrm{P}$ is positive, the operating point will move to attain MPPT and if $\Delta \mathrm{P}$ is negative, the operating point will take to reverse direction. Figure 7. describes the flow chart algorithm [7]. 


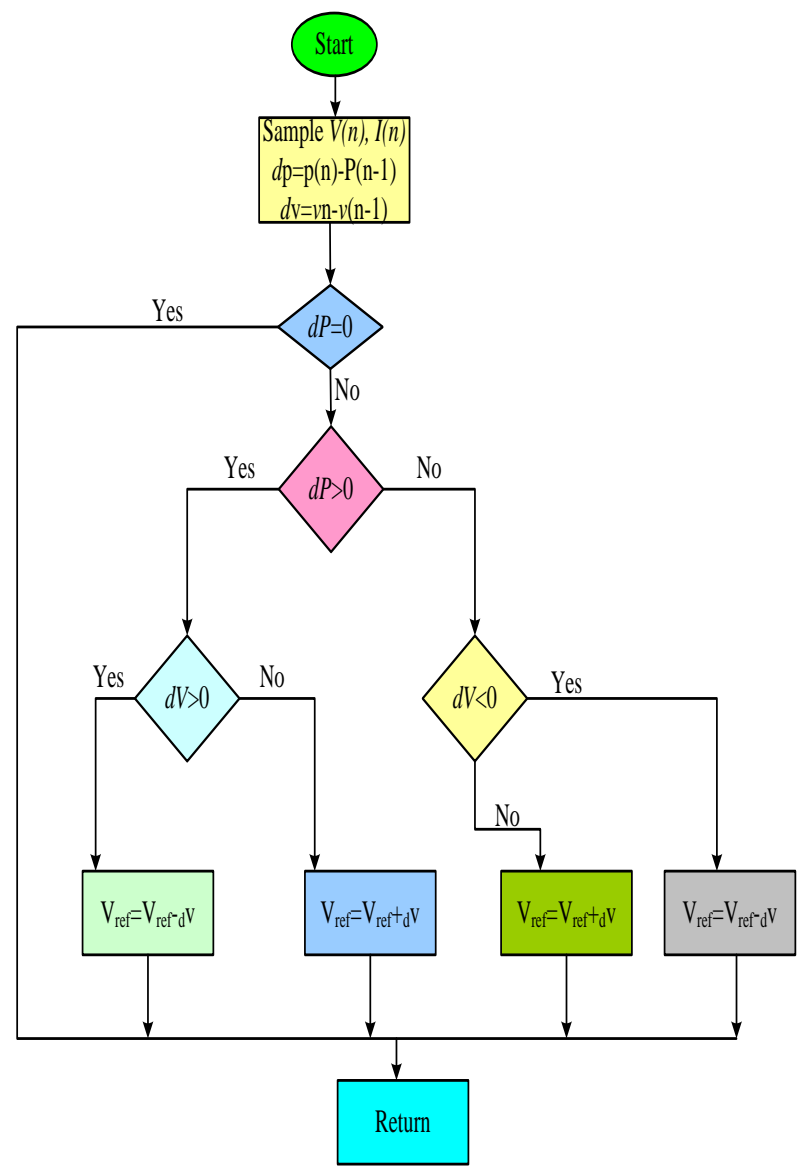

Figure 7. Flow Chart of Perturbation and Observation

\subsection{Artificial Neural Network (ANN) type of MPPT}

This type of MPPT technique is a multilayered feedback Neutral Network (MFNN) having back-propagation based network. A two-stage offline ANN will estimate the issues or level of irradiation and temperature of the MPPT of PV module voltage and current. This MPPT mechanism offers better performance under the different environmental condition and also under steady and transient states [14].

\subsection{Fuzzy Logic (FL) type of MPPT}

This is a proper way to measure an input space to output space. FL is a set theory, where a single member will have sets with a membership degree. An FL-based MPPT includes blocks like fuzzification, inference and defuzzification [13, 14].

\subsection{Particle Swarm Optimization (PSO) type of MPPT}

This type of algorithm helps to minimize the steady-state oscillation to zero, if the MPP is attained. This mechanism tracks MPP under extreme climate conditions like isolation, fluctuation and also under partial shading. This mechanism tracks the MPP successful but at a lower speed.

\section{EXISTING RESEARCH WORK}

This section discusses the recent research work on DC-DC converter efficiency, maximum power tracking in the photovoltaic cell. In this recent IEEE, journals are surveyed and discussed as below.
The concept of an ultra large step up switched capacitor DCDC converter along with coupled inductor for AC energy sources is presented in Liang et al. [15]. The ultra large voltage conversion ratio (ULVCR) presented with an integration of switched capacitor circuit with a coupled inductor mechanism. The circuit has a parallel connection of many forward converters and each converter contains a switched capacitor circuit. The boost converter switch will activate all the stages. During the operation, it is analyzed that the leaked coupled inductor energy was recycled to load and efficiency is more than $95 \%$.

A DC bus based photovoltaic power generation connected to the modular grid system is presented in Zhang et al. [16]. The mechanism intended to reliability and efficiency enhancement in distributed micro generation. In this, DC bus was incorporated with inputs and outputs of DC-AC inverter and DC-DC converter respectively. Coupling of AC is identified among the parallel operated inverters. The current decompiling method was introduced to adopt the regulating current. For efficiency enhancement, optimal control mechanism was adopted. This mechanism of grid modularization was connected to the photovoltaic method, and steady \& dynamic state analysis was carried out. The analysis and the results of experiments suggested that the mechanism outcome is with better control strategies.

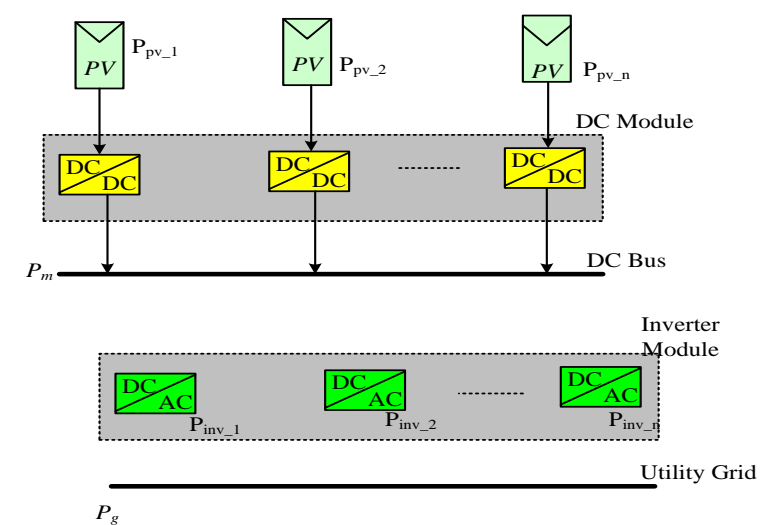

Figure 8. Zhang et al. [16] Modular Grid and PV System Configuration

The figure 8. shown above represents the modular structure of Zhang et al. [16] work. The grid connected to PV array interfaced with DC bus composed of DC-DC converter output and DC-AC inverter module sharing without any transformer isolation. These converters are common to DC bus while the inverters are distributed and modularized rather than a centralized inverter. The maximum power point tracking and voltage step up was achieved with a DC-DC converter. The inverter modules injects a sinusoidal AC as utility grid along with unity power factor and regulated DC bus voltage.

In the work of Liu et al. [17] mentioned the concept of building integrated photovoltaic (BIPV) system and also the design aspects of BIPV. The work of the author focused on the current issues like reliability and efficiency. The study was intended to solve the above issues and achieving the photovoltaic DC building model (PVDCBM). The experimental results are verified, the validity and feasibility of the novel concept. 
Table 1. Gives the Parameter Selection of Liu et al. [17] Work

\begin{tabular}{|c|c|}
\hline \multicolumn{2}{|c|}{ PVDCBM } \\
\hline Parameters & Values \\
\hline Maximum Output Power & $200 \mathrm{~W}$ \\
\hline Input Voltage & $20-50 \mathrm{~V}$ \\
\hline Output Voltage & $200 \mathrm{~V}$ \\
\hline Maximum Duty Ratio & 0.85 \\
\hline Switching Frequency & $100 \mathrm{kHz}$ \\
\hline \multicolumn{2}{|c|}{ Centralized Inverter } \\
\hline Parameters & Values \\
\hline Maximum Output Power & $1000 \mathrm{~W}$ \\
\hline Input Voltage & $200 \mathrm{~V}$ \\
\hline Switching Frequency & $10 \mathrm{kHz}$ \\
\hline Grid Voltage & $100 \mathrm{v}$ \\
\hline Grid Frequency & $50 \mathrm{~Hz}$ \\
\hline
\end{tabular}

In Kadri et al. [18], presented non-dissipative string current diverter, in order to solve the efficiency issue in power generation with PV modules. In this DC-DC converter is connected in between the PV module and the grid. This connection will bring the optimum efficiency by MPPT technique. From the analysis of simulation and experimental results helps to verify the effectiveness of the method. The final analysis of the work is done over the irradiation condition and come with effective and significant results.

Author Wai et al. [19] expressed the idea of standalone PV system to attain the highly efficient power generation. In this, a power circuit consists of PWM and step up converter to design inverter based flexible, expandable PV system for power generation. The main usage of the DC-DC converter in this method was to bring the enhanced conversion efficiency like boost converter that permits the parallel connection of PV array and decouples along with the PWM inverter design. Also in this, active system for sun radiation tracking which results in maximum power efficiency. The validation and verification of the experimental results says that the performance of the standalone PV system is significant in MPP.

Das and Agarwal [20] have given a $3 \phi$ standalone PV system concept presented below uses a highly efficient high gain dc-dc converter. This converter is in forward and bidirectional way. In this, high voltage converter is used between the PV module and the battery. This method offers desired power tracking.

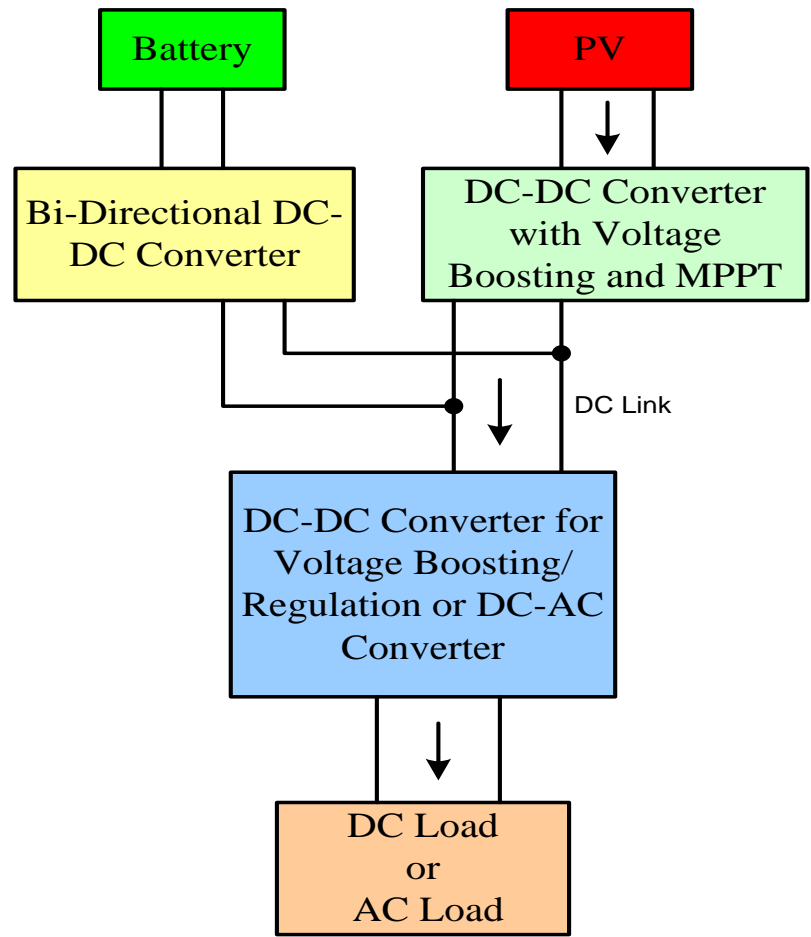

Figure 9. Typical Power Conversion Configuration for a Stand-Alone PV System by Das and Agarwal [20]

In this, bi-directional DC-DC converter and the battery backup is connected to the DC link.

Choi [21] presented the fast-dynamic response featured DCDC converter for low voltage PV source. The power switches voltage will be reduced at low voltage end. The reduction in switching power losses will improve the power efficiency.

The concept of the grid interfaced boost half bridge micro inverter for PV system and the control implementation of it is presented in Jiang et al. [22]. The micro inverter is used to attain the highly efficient low-cost interface between the PV module.

The combined work by J M Kwon, B H Kwon and Nam [23] given an efficient mechanism of DC-DC converter for PV modules. This converter implements the active clap circuit and results in more than $90 \%$ of efficiency.

To meet the requirements of high efficiency for various PV applications, LaBelle et al. [24] given the bidirectional switch based resonant converter for a broad range of voltage inputs. The mechanism achieves high efficiency of $98 \%$ under nominal voltage.

The mechanism of high-frequency link based grid connected to a photovoltaic system with low frequency and de link capacitor ripple free MMPT was given in Shi et al. [25]. In this, a dc link voltage synchronizing control was developed to mitigate the issues caused due to reduced capacitance. Later a dynamic model for prevention of significant voltage variation was given. The MPPT algorithm is validated with converter performance.

The combined work of Patel and Shireen [26] presented the PV module characteristics analysis and determination of short-circuit current to have MPPT. Under the MPP short circuit current, load and open circuit voltage are identified.

Trejos et al. [27] have presented the DC link voltage 
interfaced for grid-connected PV systems with DC/DC converters like Zeta, Cuk, and SEPIC. This system reduces the current ripples occurred due to load and PV array.

Author Liang et al. [28] have introduced a DC/DC converter to process the energy operated by PV module.

In the recent work of Zhang et al. [29] presented the 3phase DC-DC converter for electronic transformer applications. In this a phase shift (dual phase) method is described to balance and control the sub module capacitor voltage and output power respectively. The research results are validated with the theoretical results.

The work of Vinnikov et al. [30] states the Quasi Z source DC-DC (Series resonant) converter that offers high performance in PV based applications. With this model, author has achieved the ripple free output voltage of $400 \mathrm{~V}$ in just six input voltage variations i.e. from $10 \mathrm{~V}$ to $60 \mathrm{~V}$. The prototype of converter has gained the efficiency of nearly $98 \%$.

The work presented in Alassi and Massoud [31] has given the concept of DC-DC converter modelling for the application of $\mathrm{PV}$. In this a mathematical modelling concept is introduced for SEPIC and Cuk converter. The performance of these converters is compared with duty cycle and input voltage.

In Ujita et al. [32] a complete integrated GaN based Power integrated circuit is used to attain high efficiency in DC-DC converter. In this, the IC was subjected to $12 \mathrm{~V}$ to $1.8 \mathrm{~V}$ and observed that IC is exceeding the limit of Si. From this the size of power circuit is reduced more than $50 \%$.

\section{ISSUES IN PV SYSTEM}

We know that the solar energy is easily available and it is free of cost. By using the energy conservation law, it can be possible that the solar energy can be used to produce the electrical energy and such systems are considered as photovoltaic systems. The main drawback of the PV system is that the power efficiency decreases, when the climatic conditions vary and also the shadows on the PV arrays also decreases its efficiency. Some of the important issue in PV systems is given below [7].

\subsection{Intermittent Generation}

The constantly changing environment condition needs proper weather forecast to schedule the better power generation.

\subsection{Transmission System Issue}

The transmission of high energy over the existing transmission line is quite tough and is one of the notable points in PV system.

\subsection{Distribution System Issues}

The distribution of power to the different sectors is very tough in PV system.

\subsection{Integrating Energy Storage}

To attain the better efficiency, we can integrate grids and PV module but the storage system for this generated energy is very difficult.

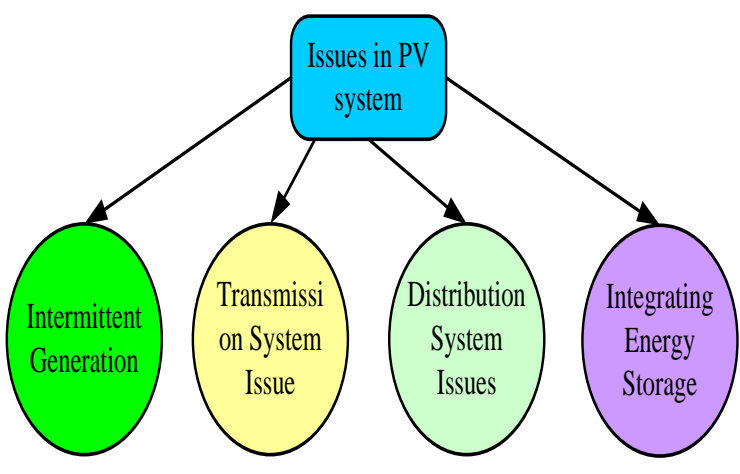

Figure 10. Issues of PV Systems

\section{PV SYSTEM ADVANTAGES AND DISADVANTAGES}

The following table gives the PV system advantages and disadvantages.

Table 2. PV System advantages along with disadvantages

\begin{tabular}{|ll|l|}
\hline \multicolumn{2}{|c|}{ Advantages } & \multicolumn{1}{|c|}{ Disadvantages } \\
\hline$>$ & $\begin{array}{l}\text { Decreases electricity bill } \\
\text { Decreased PV panels } \\
\text { cost has made } \\
\text { affordable. }\end{array}$ & $\bullet \begin{array}{l}\text { Cost is high } \\
\text { Needs proper rooftop to } \\
\text { install it. }\end{array}$ \\
$>\begin{array}{l}\text { Produces free electricity. } \\
\text { Generates power even in } \\
\text { cloudy condition. }\end{array}$ & & $\begin{array}{l}\text { Roof or tree shades } \\
\text { may affect the power } \\
\text { generation. } \\
\text { Less maintenance } \\
\text { needed } \\
\text { Environmental friendly. }\end{array}$ \\
\hline
\end{tabular}

\section{RESEARCH GAP}

Power efficiency is a key driving force due to the continual increase of energy consumption and costs. Therefore, now the development focuses on high-efficiency power supplies, which enable cost and cooling effort reduction. From the survey, research carried by various researchers, it is known that efficiency is the major concern for power generation. Many efficiency enhancement mechanisms are presented but are failed to provide the accuracy. The recent survey analysis says that the efficiency optimization is still an active topic for research in PE.

\section{FUTURE RESEARCH SCOPE}

The work that had been carried out by the researchers, the designing of MPPT controller, should be extended by tracking a larger number of input parameters which are varying to the time such as parameters variations of the system.

$>$ Can computationally evolve up with a technique for MPP distributed architecture of DC-DC controller with the aid of mathematical modelling.

$>$ Can apply multivariate optimization technique on multiple conditions of power and voltage for evolving up with a predictive technique ensuring efficient controller synchronization.

$>$ Can perform comparative analysis of the outcome of the proposed system with the existing significant system. 


\section{CONCLUSION}

The Photovoltaic systems are offering a better solution to the largest issue of environment i.e., electrical power demand. To meet this power demand, many efficiency enhancement mechanisms of PV systems are presented. Among these mechanisms, the Maximum Power Point Tracking is most trustworthy and it is best suited for PV system. The use of DC-DC converter in between the grid and PV module can bring efficiency optimization. This survey paper gives the existing MPPT mechanisms for power efficiency enhancement. The recent research work provides an idea of the research gap. By considering the research gap, future scope of research is given.

\section{REFERENCES}

[1] Mohan, Ned, and Tore M. Undeland. Power electronics: converters, applications, and design. John Wiley \& Sons, 2007.

[2] Erickson, Robert W., and Dragan Maksimovic. Fundamentals of power electronics. Springer Science \& Business Media, 2007.

[3] Rashid, Muhammad H. Power electronics: circuits, devices, and applications. Pearson Education India, 2009.

[4] Zhou, Siyuan, and Gabriel A. Rincon-Mora. "A high efficiency, soft switching DC-DC converter with adaptive current-ripple control for portable applications." IEEE Transactions on Circuits and systems Part 2 express BRIEFS 53.4, 319, 2006.

[5] Bose, Bimal K. "Power electronics and motor drives recent progress and perspective." IEEE Transactions on Industrial Electronics 56.2, pp. 581-588, 2009.

[6] Selvaraj, Jeyraj, and Nasrudin A. Rahim. "Multilevel inverter for grid-connected PV system employing digital PI controller." IEEE Transactions on Industrial Electronics 56.1, pp.149-158, 2009

[7] Zhao, Qun, and Fred C. Lee. "High-efficiency, high stepup DC-DC converters." IEEE Transactions on Power Electronics 18.1, pp. 65-73, 2003

[8] Zhou, Siyuan, and Gabriel A. Rincon-Mora. "A high efficiency, soft switching DC-DC converter with adaptive current-ripple control for portable applications." IEEE Transactions on Circuits and Systems Part 2 Express Briefs 53.4 319, 2006

[9] Blaabjerg, Frede, Zhe Chen, and Soeren Baekhoej Kjaer. "Power electronics as efficient interface in dispersed power generation systems." IEEE transactions on power electronics 19.5, pp. 1184-1194, 2004

[10] Koutroulis, Eftichios, Kostas Kalaitzakis, and Nicholas Enslin, Johan HR, et al. "Integrated photovoltaic maximum power point tracking converter." IEEE Transactions on Industrial Electronics 44.6, pp. 769-773, 1997

[11] De Brito, Moacyr Aureliano Gomes, et al. "Evaluation of the main MPPT techniques for photovoltaic applications." IEEE transactions on industrial electronics 60.3, pp.1156-1167, 2013

[12] Dolara, A., R. Faranda, and S. Leva. "Energy comparison of seven MPPT techniques for PV systems." Journal of Electromagnetic Analysis and Applications, 2009
[13] De Brito, Moacyr AG, et al. "Comparative analysis of MPPT techniques for PV applications." Clean Electrical Power (ICCEP), 2011 International Conference on. IEEE, 2011.

[14] De Brito, M. A., Sampaio, L. P., Luigi, G., e Melo, G. A., \& Canesin, C. A. Comparative analysis of MPPT techniques for PV applications. In Clean Electrical Power (ICCEP), 2011 International Conference on (pp. 99-104). IEEE, 2011

[15] Liang, T. J., Chen, S. M., Yang, L. S., Chen, J. F., \& Ioinovici, A. (2012). Ultra-large gain step-up switchedcapacitor DC-DC converter with coupled inductor for alternative sources of energy. IEEE Transactions on Circuits and Systems I: Regular Papers, 59(4), 864-874.

[16] Zhang, L., Sun, K., Xing, Y., Feng, L., \& Ge, H. A modular grid-connected photovoltaic generation system based on DC bus. IEEE transactions on power electronics, 26(2), 523-531, 2011

[17] Liu, B., Duan, S., \& Cai, T. Photovoltaic DC-buildingmodule-based BIPV system-Concept and design considerations. IEEE Transactions on Power Electronics, 26(5), 1418-1429, 2011.

[18] Kadri, R., Gaubert, J. P., \& Champenois, G. Nondissipative string current diverter for solving the cascaded DC-DC converter connection problem in photovoltaic power generation system. IEEE Transactions on Power Electronics, 27(3), 1249-1258, 2012.

[19] Wai, R. J., Wang, W. H., \& Lin, C. Y. (2008). Highperformance stand-alone photovoltaic generation system. IEEE Transactions on Industrial Electronics,55(1), 240-250.

[20] Das, M., \& Agarwal, V. Novel High-Performance StandAlone Solar PV System With High-Gain High-Efficiency DC-DC Converter Power Stages.IEEE Transactions on Industry Applications, 51(6), 4718-4728., 2015

[21] Choi, W. Y. High-Efficiency DC-DC converter with fast dynamic response for low-voltage photovoltaic sources. IEEE Transactions on Power Electronics, 28(2), 706-716, 2013

[22] Jiang, S., Cao, D., Li, Y., \& Peng, F. Z. Grid-connected boost-half-bridge photovoltaic microinverter system using repetitive current control and maximum power point tracking. IEEE transactions on power electronics,27(11), 4711-4722, 2012.

[23] Kwon, J. M., Kwon, B. H., \& Nam, K. H. Highefficiency module-integrated photovoltaic power conditioning system. IET Power Electronics,2(4), 410420, 2009.

[24] LaBella, T., Yu, W., Lai, J. S. J., Senesky, M., \& Anderson, D. A bidirectional-switch-based wide-input range high-efficiency isolated resonant converter for photovoltaic applications. IEEE transactions on power electronics, 29(7), 3473-3484, 2014

[25] Shi, Y., Li, R., Xue, Y., \& Li, H.. High-frequency-linkbased grid-tied PV system with small DC-link capacitor and low-frequency ripple-free maximum power point tracking. IEEE Transactions on Power Electronics,31(1), 328-339. 
[26] S. Patel andW. Shireen, "Fast converging digital MPPT control for photovoltaic applications," in Proceedings of the IEEE Power and Energy Society General Meeting, pp. 1-6, San Diego, Calif, USA, July 2011.

[27] A. Trejos, C. A. Ramos-Paja, and S. Serna, "Compensation of DC-link voltage oscillations in gridconnected PV systems based on high order $\mathrm{dc} / \mathrm{dc}$ converters," in Proceedings of the IEEE International Symposium on Alternative Energies and Energy Quality (SIFAE '12), pp. 1-6, Barranquilla, Colombia, October 2012.

[28] Z. Liang, A. Q. Huang, and R. Guo, "High efficiency switched capacitor buck-boost converter for PV application," in Proceedings of the 27th Annual IEEE Applied Power Electronics Conference and Exposition (APEC '12), pp. 1951-1958, Orlando, Fla, USA, February 2012.

[29] J. Zhang; Z. Wang; S. Shao, "A Three Phase Modular
Multilevel DC-DC Converter for Power Electronic Transformer Applications," in IEEE Journal of Emerging and Selected Topics in Power Electronics , vol.PP, no.99, pp.1-1, 2016

[30] D. Vinnikov; A. Chub; E. Liivik; I. Roasto, "HighPerformance Quasi-Z-Source Series Resonant DC-DC Converter for Photovoltaic Module Level Power Electronics Applications," in IEEE Transactions on Power Electronics , vol.PP, no.99, pp.1-1, 2016

[31] A. Alassi and A. Massoud, "Modelling of DC-DC converters with continuous input current for high power PV applications," IEEE Symposium on Computer Applications \& Industrial Electronics (ISCAIE), Penang, Malaysia, pp. 171-176, 2016

[32] S. Ujita, "A fully integrated GaN-based power IC including gate drivers for high-efficiency DC-DC Converters," IEEE Symposium on VLSI Circuits (VLSICircuits), Honolulu, HI, USA, pp. 1-2, 2016. 